\title{
ASPECTOS TIPOLÓGICOS DEL TEXTO INSTRUCTIVO (A PROPÓSITO DEL PROSPECTO PARA MEDICAMENTO DE USO HUMANO)
}

\author{
Juan Pedro Gómez \\ (Universidad de Murcia)
}

\begin{abstract}
RESUMEN
The present article is a study that aims to characterize the textual structure (macroestructure and superestructure) of the pharmaceutical prospectus, dismantling the textual plan and determining the differentials elements of that kind of instructive text. The configurarion of the type and the stablishment of its individuality is based on the integration of criteria and standard elements. This essays shows how the complementary perspectives can explain, with coherence, the outline of the type.
\end{abstract}

\section{CONSIDERACIONES PREVIAS}

Conscientes del confusionismo existente en la utilización de las expresiones tipo de texto y clase de texto, relacionadas con una amplia diversidad de conceptos, optamos por la expresión clase de texto, entendida «como designación, conscientemente vaga, para toda forma de texto, cuyas características pueden fijarse mediante la descripción de determinadas propiedades, no válidas para todos los textos, independientemente de si estas propiedades pueden concebirse teóricamente y de qué manera, dentro del marco de una tipología textual» (H. Isenberg, 1983: 101 ), para enmarcar provisionalmente nuestro objeto de estudio y descripción en una primera fase de selección y muestreo.

Como unidad básica de comunicación lingüística, o secuencia de signos que produce sentido, el texto responde a un plan textual de carácter unitario, en el que sus características constitucionales de unidad superior sin límites precisos, su estructura compacta con alta coherencia y fuerte cohesión interna, así como 
su sometimiento a una codificación o una intercodificación de carácter lingüístico (J.S. Petöfi y A. García Berrio, 1978: 55-57), le otorgan una individualidad lo suficientemente distintiva, y por ende dependiente de un aire de familia, como para constituirse en miembro diferencial de una clase, con la posibilidad teórica, macroestructural y superestructural, de tipologización científica.

La construcción del tipo se manifiesta como modelo ideal, como aglutinador paradigmático de los caracteres esenciales de todos los elementos de igual naturaleza. El tipo, con una relación de inclusión respecto a su tipología correspondiente, y su similaridad clasemática, incluye, a su vez, subtipos múltiples que deben justificarse en el marco de la tipología superior inmediata, ajustándose, en el caso concreto de las tipologías textuales, a los requisitos tendentes a eliminar la ambigüedad y acrecentar el rigor tipológico (H. Isenberg 1983: 117).

Pero, mientras el marco general tipológico no se diseña, y se evita el problema de la homegeneidad, por la exigencia analítica de la exhaustividad descriptiva, optamos en primer lugar por una aproximación de la clase textual que nos permita una clasificación genérica en la que tengan cabida fenómenos de distintas categorías.

$\mathrm{Si}$, contectando con Wittgenstein, «el mundo es mi mundo» y el yo filosófico no es otra cosa que límite del mundo (1957-1984: 163-167), el texto es una productividad intencional individualizada, en un acto de expresión que deriva de un acto mental o textura (M. Metzeltin, 1988: 24) de carácter conceptual o proposicional, con una estructura estable, regular y predecible en su iteración familiar, tanto en lo referente al mensaje marco («apariencia física del portador de información»o «texto-a-decodificar», «autoseñalamiento perceptible»), como al mensaje exterior ( «conjunto de disparadores de estilo y de técnica decodificadora») y el mensaje interior («lo que se quiere transmitir») (D.R. Hofstadter, 1979-1989: 183-190).

La estandarización textual conlleva una forma que nos informa de la naturaleza de cualquier clase de texto a través de su «aspecto». Por ello, desde una perspectiva «clasemática», apoyándonos en la fórmula iconográfica de Shahn: Forms is the visible shape of content (R. Arnheim, 1854-1974: 115), podemos concluir que un conjunto de textos se diferencian entre sí por una serie de elementos con relevancia perceptual: por una diferenciación formal y explícita de su contenido, no percibiéndose nunca la forma como forma de sólo una cosa concreta, sino siempre como de una clase de cosas.

El aire familiar y la clase, con o sin tipologización, se genera, se reconoce y se acepta por la fuerte cohesión de la forma perceptual o estructura del texto. Así, en una transposición de percepción gestalt (I. Rock, 1975 y 1984), la constancia textual responderá a un principio de organización evidentemente pragmático.

A veces, como en un círculo vicioso, texto concreto, tipos de texto, tipologías 
y sistemas de clasificación complejos se interfieren negativamente en el marco de la teoría del texto, impidiendo, en muchas ocasiones, un desarrollo teórico adecuado y pertinente. Sin embargo, la aproximación al fenómeno textual concreto, aunque sea a través de una clase intuitiva, global e imprecisa, nos parece rentable y necesario en el liminar del protocolo analítico.

Como estudio previo a la teorización tipológico-textual, es necesario el análisis minucioso de un amplio abanico de textos que, cuantitativa y cualitativamente justifiquen la operatividad de estandarización y clasificación tipológica.

Optamos por el «prospecto de especilidades farmaceúticas y demás medicamentos de fabricacion industrial» (en lo sucesivo: «prospecto- $m$ ») como objeto inmediato de estudio.

Si todo «prospecto» responde a una caracterización sémica de <anuncio breve $>$, <impreso en papel $>$ (<pequeño formato $>$ ) e $<$ instrucción $>$, la restricción del marco medicamentoso, en el uso cotidiano, delimita un poco más el campo de actuación con aportaciones semióticas direccionales (emisor-destinatario) y contextuales lo suficientemente relevantes como para esclarecer rasgos de pertinencia tipológica.

Los efectos comunicativos del prospecto como texto, su sentido en la acepción de Coseriu (1977: 220-221), diseñan algunos aspectos de funcionalidad tipológico-textual que favorecen la representatividad de la geometría del texto encarnado y, por tanto, la posibilidad de medirlo, asociarlo y ubicarlo.

La urgencia comunicativa del texto y su disponibilidad lectora (E.Ramón Trives, 1979: 184-189), sintetizada estructuralmente y sometida a soporte documental, supone el discernimiento lector; todo un proceso de inversión textual que conduce al plan-pre-ejecutado y pone de manifiesto Ia hipotética reconstrucción lógico-semántica y la intencionalidad extralingüística.

Junto a los aspecto relacionados con el contenido proposicional/ilocutivo específico y los elementos estructurales distintivos (A. Vera, 1990; J.P. Gómez, 1991), convenimos con el prof. Vera Luján que «la institucionalización de un determinado tipo de relación comunicativa acaba por fijar un cierto tipo de esquemas normaticos a los que un acto discursivo debe acomodarse para ser reconocido colectivamente como formando parte de un <género> preciso» (1990: 69). Este esquema de organización suplementaria, el denominado superestructura textual (T.A. van Dijk, 1978: 141-173), aunque todavía no sea definitivo ni excluyente, se justifica, en su inmanecia, por la base psicológica y los procesos cognitivos propios, $\mathrm{y}$, respecto a su reconocimiento pragmático, por la utilización y aplicación, consciente o inconsciente, del sujeto social (la intencionalidad del productor, la aceptabilidad del receptor-destinatario-usuario y la situacionalidad comunicativa) (R.A. Beaugrande, 1981: 31).

Una primera aproximación física al prospecto- $m$ nos pone en contacto con un texto «soportado» o fijado materialmente sobre un soporte que puede utilizarse básicamente como consulta; se trata de un verdadero documento (N. Amat, 1988: 
19) que se constituye como elemento testimonial, hacedor de cultura, medio de información y, fundamentalmente, como instrumento facilitador de la comunicación humana entre unos emisores siempre técnicos y unos destinatarios la mayor parte de las veces ajenos al contenido tratado.

Además, representación ordenada y formalizada de un campo de conocimiento, responde también a la exigencia de una fácil utilización (E. Currás, 1988; 49).

El texto-documento-prospecto- $m$ se encuentra depositado en el interior de todos los envases destinados a especilidades farmaceúticas o medicamentos de uso humano. El prospecto- $m$ se constituye funcionalmente como elemento adherente del objeto-medicamento y, en tanto que literatura especial no localizable en los canales habituales de venta o consulta: librerías, kioskos, bibliotecas, etc., tiene, sin embargo, la facilidad de ligarse al producto, pudiéndose adquiri, a diferencia de otras clases de prospectos, conexionado al objeto-medicamento del que depende, siempre y cuando éste pueda ser conseguido de acuerdo con la normativa social.

Según se va trasformando el paradigma social, y va enriqueciéndose la conciencia colectiva, de acuerdo con un estado de equilibrio entre el plan proyectado por el emisor (enunciador) y la aceptabilidad del destinatario, se hace más patente el desvanecimiento de la fusión parasitaria del prospecto- $m$ para subrayarse el valor simbiótico-pragmático de la relación establecida entre el texto y el producto al que hace refencia y/o viceversa.

\section{ESTRUCTURAS DE APERTURA Y CIERRE}

El prospecto- $m$ pertenece a la clase de textos de carácter concluso, enmarcado por una estructura global de apertura y cierre.

La apertura del prospecto- $m$ está constituida por un entramado de semiótica mixta o de código heterogéneo en la estructura superficial del texto, formado por elementos lingüísticos con estructuras gráfico-tipográficas y cromáticas convencionales: tamaño grande para la denominación del producto y tamaños proporcionalmente menores para la denominación técnica y la presentación del medicamento, así como diversos tipos, cuerpos y estilos de caracteres en línea estética sobria, tradicional y poco dada al diseño creativo.

Las categorías correspondientes al nivel léxico están conformadas por nombres propios, comunes, concretos de materia y genéricos individuales, adjetivos (en muy raras ocasiones, ej.: «uso tópico») y numerales cardinales (representados con cifras, influso los treinta primeros que constan de una sola palabra gráfica, ej.: «Feldene 20»), con ausencia de verbo y de elemento deíctico (valor amplificador propio del lenguaje publicitario).

Por otra parte, los símbolos visuales, signos categoremáticos de carácter 
icónico, que también forman parte del encabezamiento o presentación de la apertura textual, responden a una codificación estricta y restringida, cuyo listado suele ser ajeno a la competencia del destinatario' no avisado:
: Especialidades que necesitan receta médica
D : Receta de psicótropos ${ }^{2}$
* : Condiciones especiales de conservación (frigorífico)
(1) : Receta de psicótropos ${ }^{3}$
: Receta de estupefacientes
X: Caducidad inferior a 5 años
DH: Diagnóstico hospitalario

ECH Especialidad control médico
TLD Tratamiento de larga duración

En el encabezamiento de los prospectos- $m$, correspondientes a los prospectos objetuales que se hayan en el mercado farmacéutico ${ }^{4}$, el receptor puede captar de forma casi simultánea, sin sometimiento a un orden lineal, un constructo de representación introductoria con distintos valores microcomponenciales.

\section{ELEMENTOS DEL ENCABEZAMIENTO}

1. Símbolo/s gráfico/s: Listado de signos icónicos combinables (marcas distintivas condicionantes del acto social de la adquisición; referentes semánticos de atención especial.

2. DENOMINACIÓN del producto: a. Nombre comercial (común o inventado); b. Nombre técnico. $<<$ Mayúsculas: Gran (mayor) Tamaño/ Negrita $>$.

3. Opcional, a veces en el cierre: logotipo, marca o nombre del fabricante del medicamento.

4. Opcional, a veces en el cierre: símbolo $\mathbb{B}($ Registro de la Propiedad Industrial).

\footnotetext{
Listamos según el Catálogo de Especialidades Farmacéuticas 1993, Consejo General de Colegios Oficiales de Farmacéuticos, Madrid.

2 Psicótropos incluidos en la lista II, III y IV del Convenio sobre sustancias psicotrópicas del 21 de febrero de 1971.

3 Psicótropos incluidos en el anexo 2 del Convenio sobre sutancias psicotrópicas del 21 de febrero de 1971.

4 Nuestro muestreo empírico se lleva a cabo al margen de las actualizaciones de las normativas legales (Directiva del Consejo 92/77, Comunidad Económica Europea; Proyecto de Real Decreto (Consejo de Colegios Oficiales de Farmacéuticos, Circular n 69/93, Madrid, 24 de marzo de 1993; Real Decreto 767/1993, de 21 de mayo, B.O.E. 2 de julio, 1993.
} 
5. Opcional, a veces en el cierre: nombre y dirección del fabricante o de la entidad fiscal.

6. Opcional: composición fundamental o básica. $<<$ Menor tamaño que letras de DENOMINACIÓN y mayor que el resto del texto $>>$.

7. Opcional: dosificación/cantidad ( $\mathrm{mg}, \mathrm{ml}, \mathrm{g} . .$. ).

8. Opcional: grupo de población al que va destinado (lactantes, niños, adultos,...)

9. Opcional: formas de presentación farmacéutica (grageas, cápsulas,...)

10. Opcional: vía de administración (oral, uso tópico, intramuscular,...)

11. Opcional: tipo de medicamento o actividad terapéutica (tensiolítico, analgésico,...)

En este conjunto de once componentes, la pertinencia lingüística nos permite la representación de una superestructura global del encabezamiento, constituida por tres categorías básicas, desarrolladas microestructualmente(1):

\section{DENOMINACIÓN}

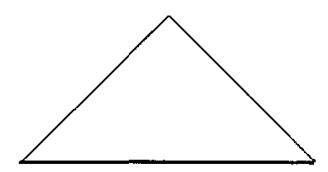

Presentación FINALIDAD

La denominación consiste en la identificación del objeto motivador del texto. Se trata de un denominador cultural, perteneciente al nivel categorial de los nombres propios, que se constituye como identificador mítico en los niveles más altos de función apelativa en el mensaje publicitario (J.M. Lotman, 1973/ 1979: 111-135), y que alcanza en la aplicación farmacéutica una gran intensidad sémica connotativa, debido a su singularidad y a su individualidad.

La distinción referencial, breve y lacónica, de la denominación («Aspirina» «Nolotil», «Valium», «Buscapina») actúa en la memoria del usuario como un gran estereotipo al que aspirar en materia de prevención y cura. La aureola mágica del nombre propio aplicado a las personas (Ullmann, 1976: 82) tiene también en cualquier clase de producto una función de identificación social, de nombramiento y reconocimiento de la propia existencia. La denominación del prospecto- $m$ funciona en el encabezamiento de forma similar a la marca publicitaria en general, convirtiéndose en una espiral sémica de carácter experiencial, fruto de las actuaciones pragmáticas en la doble vertiente de una galaxia objetual extralingüística y de una galaxia enunciativa conversacional con el intercambio de informaciones de los usuarios. 
La relación que se establece entre el usuario del medicamento (intérprete mediador o destinatario final del producto) y el texto-prospecto-m es una relación semiótica de tipo intimista y de absoluta entrega al acto mágico de la lectura iniciática ${ }^{5}$. Por parte del destinador (o del creativo destinado para el caso) no se renuncia a la técnica del marketing ni a los recursos retóricos propios de la publicidad, si bien las técnicas comerciales aplicadas al encabezamiento del propecto- $m$ son más bien mínimas, y son más los valores experienciales, privados y compartidos por difusión, los que determinan la situación comunicativa de confianza fetichista o «talismánica». La atención que el destinatario presta al prospecto-m es incluso superior a la prestada a otro tipo de prospectos normativos e instructivos. La confianza otorgada responde a la creencia en el rigor, fiabilidad y veracidad de los desarrollos temáticos llevados a cabo por el enunciador del discurso, ya que uno de los objetivos fundamentales del prospecto$m$ radica en la posibilidad de dirimir el conflicto «confianza vs desconfianza» que el usuario libra respecto a los productos farmacéuticos que desconoce o que conoce de forma disfórica.

En el encabezamiento del prospecto- $m$, la rarefacción de la palabra, evidenciada tipográficamente pero carente de todo tipo de apoyo argumental ${ }^{6}$, queda reducida a la presencia definitiva, lacónica y tremendamente sobria de la denominación, que se autoidentifica arquetípicamente y comparte su esencia (puede compartirla según los modelos) con los constituyentes presentación y finalidad que, en el esquema anterior aparecen claramente diferenciados con una tipografía jerárquica, correspondiendo al primer nivel la denominación (DENOMINACIÓN) y al segundo la presentación (Presentación) (a veces supone vía de administración) y la finalidad (FINALIDAD), que manifiesta una mayor entidad informativa que la presentación.

Así, del encabezamiento de apertura textual se deduce una relación superproposicional enunciativa con cuatro articulaciones posibles:

\section{1‥ DENOMINACIÓN}

\section{[ $\{$ Producto $\mathrm{X}\}$ ]}

Identidad absoluta (predicación circular): Arquetipo.

Ej.: Buscapina Compositum

(Léase: 1ํㅡㄴ «Este producto es Buscapina»: el nombre propio ubicado espacialmente en el prospecto- $m$ implica objeto de denominación farmacéutica; $2^{2}$, «Buscapina es Buscapina»: grado de abstracción superior referencia social estereotipada).

De interés testimonial sobre la «importancia de la marca comercial» es la opinión de W. Thomson y P. Cooper, recogida en la obra de E. Clark (1988: 277).

- Para mayor explicación sobre la denominación y el aspecto predicativo de la marca publicitaria, puede consultarse G. Péninou (1976: 95-100; 116 y ss.) y L. Sánchez Corral (1990: 207-227). 


\section{DENOMINACIÓN-Presentación}

a. $[\{$ Producto $\mathrm{X}\}<$ presentado en forma $\mathrm{Y}>$ (presupone «por vía $\mathrm{W}$ »]

Ej.: FROBEN RETARD, cápsulas

(Léase: «El producto Froben Retard, presentado en forma de cápsulas, se administra por vía oral»).

b. $[\{$ Producto $X\} \ll$ por vía $W »]$

Ej.: Clavumox. Amoxicilina + Ácido Clavulánico. VÍA ORAL.

\section{3a. DENOMINACIÓN-Presentación-FINALIDAD}

$[\{$ Producto $\mathrm{X}\}<$ presentado en forma $\mathrm{Y}>$ (presupone «por vía $\mathrm{W} \gg)$ 'es...] para... Z']

Ej.: Gelocatil. Paracetamol (D.C.I.). Comprimidos. Analgésico-Antipirético.

(Léase: «El producto Gelocatil P. se presenta en forma de comprimidos, se administra por vía oral, es analgésico y es antipirético» Implica: una acción: «quitar el dolor de cabeza», otra acción: «quitar la fiebre», ambas acciones en el marco de una macroacción: «ALIVIAR-CURAR».

\section{4a. DENOMINACIÓN-FINALIDAD}

[ $\{$ Producto $X\}$ 'es.../para... Z']

Ej. Nolotil. Analgésico.

(Léase: «El producto Nolotil es analgésico (para "quitar el dolor")》).

Como texto superestructurado, el prospecto- $m$ dispone sus estructuras de apertura y de cierre de forma sintética respecto al desarrollo instructivo del mismo (2):

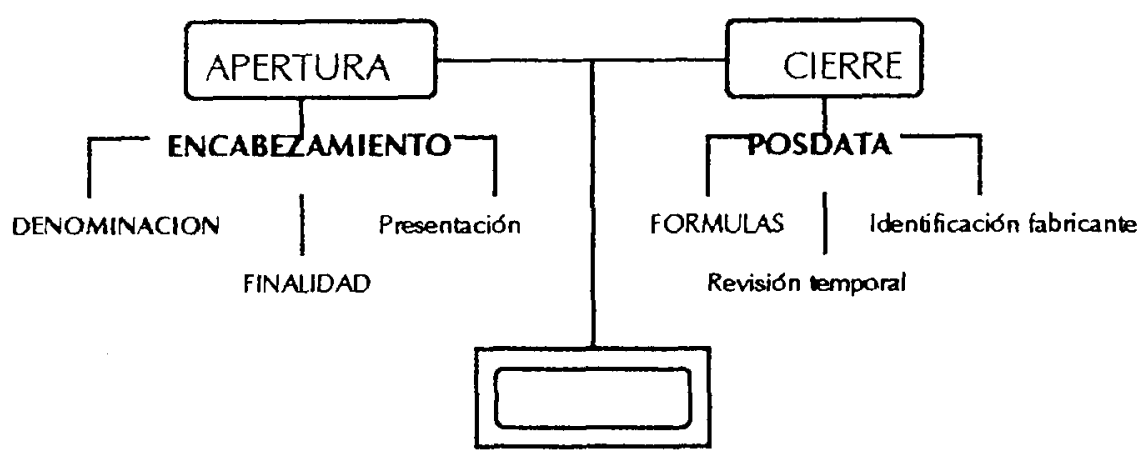

En la estructura subyacente, el marco de integración global o macroestructura global del texto del «encabezamiento» (microtexto respecto al conjunto del textoprospecto- $m$ ) tiene una correspondencia de desarrollo proposicional coincidente 
con la superestructura, representable semánticamente con un esquema frástico muy simple: //Presentación de un Medicamento//.

El nivel de organización estructural correspondiente a la superestructura, no siempre rastreable en cualquier tipo de textos, es en sí mismo un determinante específico del tipo. Apunta, acertadamente, Vera Luján (1990:68) cómo el grado de socialización y de relevancia colectiva constituye una especie de codificación suplementaria añadida a la macroestructura.

La estructura del encabezamiento, en el caso que nos ocupa, se manifiesta, por lo tanto, peculiar y distintiva en el seno de la subclase encabezamientos de la clase aperturas.

Podemos concluir, en este primer nivel de apertura textual, que el enunciador responde a las preguntas latentes del posible comprador del producto y lector del prospecto con el encabezamiento, siendo la unidades semánticas de "identificación", "finalidad" y "forma" verdaderas funciones axiales del encabezamiento de apertura (3):

(3)

1. ¿Cómo se llama este producto (medicamento)?

¿Cómo lo puedo distinguir de otros?

Definición de un elemento concreto de la clase medicamento

2. ¿Para qué sirve este medicamento?

¿Qué función terapéutica tiene?

Finalidad terapéutica

3. ¿Qué forma farmacéutica adopta?

¿Cuál es la vía de incorporación al cuerpo humano?

Forma industrial conferida y adoptada

En el cierre del prospecto-m, la posdata se configura como un constituto múltiple de elementos normativos, dispares y constantes. Junto a la identificación del fabricante industrial del producto-medicamento y a la fecha de revisión temporal del mismo, resultan de interés dos fórmulas, con sus proposiciones correspondientes idénticas en todo tipo de prospecto- $m$. Libres de exigencias jerárquicas expositivas, la primera es una auténtica fórmula de cortesía que centra el interés y la intencionalidad del emisor, al margen de las funciones de apertura y relacionándose, pragmáticamente, con la clase «medicamentos para uso humano».

La categorización del miembro social determinado por el lexema «niño» implica en el semema los semas aspectuales o virtuemas de /debilidad/, / desamparo/, /inconsciencia/, /irresponsabilidad/y /atrevimiento/, aspectos éstos 
de carácter disfórico que el enunciador prevé que repercutan en una acción finalista-eufórica, a través de implicaturas de carácter pragmático.

La proposión:

\section{LOS MEDICAMENTOS DEBEN MANTENERSE FUERA DEL ALCANCE DE LOS NIÑOS}

es una expresión genérica y universal añadida al texto, con una clara acción responsabilizadora. Con el acto ilocucionario «aconsejar», en su modalidad lógicamente obligativa, se pretende que el receptor actúe espacialmente sobre el medicamento, ubicándolo fuera del alcance de los niños.

El hecho de que la frase aparezca lematizada y con un tratamiento tipográfico distintivo (negrita, letras mayúsculas y a veces recuadrada) responde a un tratamiento de carácter apelativo-semiótico, que, a la manera de una deíxis vocativa, trata de llamar la atención del destinatario (lector) y forzarlo a actuar en un «aquí» ('en cualquier parte') y en un «ahora» ('siempre') absolutos y extralingüísticos.

Para que la finalidad del acto linguístico (D. Viehweger, 1983: 230-232) se logre («requerir a alguien a realizar una determinada acción») es necesario que el receptor conozca la intencionalidad del emisor que, en este caso, es de «prevención sanitaria», lo que en «gramática de casos» se entendería como una acción lingüística de «imposición benefactora», en la que «niños» tendría la categoría de //benefactivo//.

La reducción informativa de la fórmula de cortesía es //Prevención (infantil)//, síntesis temática de una actitud de comportamiento social, resuelta en microestructura de acción, por la que se interpreta un fenómeno de realidad, se adopta un compromiso social y se invita a asumir el mismo compromiso frente al mismo fenómeno.

La siguiente fórmula es de tipo informativo en su primera manifestación, enfatizando la carencia de condicionalidad, y de tipo normativo-obligativo en al segunda (4):

a. SIN RECETA MÉDICA. («Este medicamento puede adquirise sin necesidad de presentar receta médica»).

b. CON RECETA MÉDICA. ( «Este medicamento sólo se puede adquirir presentando receta médica» = debe adquirirse = tiene que (forzosamente) adquirirse con receta médica).

Ambas expresiones se exponen sin referente verbal explícito. La fórmula a. es una construcción impersonal de probabilidad que se inviste de autorización, 
mientras que la fórmula $b$. supone, en el marco contextual, una perífrasis modal obligativa por conocimiento sociocultural del destinatario; expresión concreta que implica al referente concreto. Si y sólo «con receta médica» tendrá satisfactoriedad el acto de adquisición.

Dada que este tipo de fórmulas se encuentra ubicado en el cierre del prospecto$m$ y que las referencias al tópico central del texto ya han sido lo suficientemente amplias, la concisión y la claridad del estilo quedan justificadas.

El esquema macroestructural del cierre queda como sigue (5):

(5)

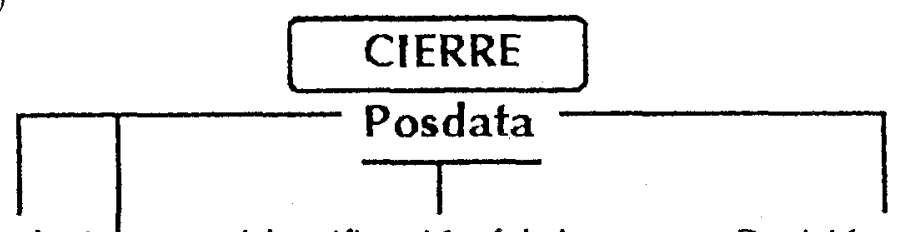

Fórmula 1

Identificación fabricante

Revisión temporal Fórmula 2

Los núcleos macroestructurados correspondientes a «Fórmula» (1 y 2), «Identificación fabricante» $\mathrm{y}$ «Revisión temporal» son /Prevención/, /Obligación/ y/Garantía/.

\section{DINAMIZACIÓN TEXTUAL DEL DESARROLLO}

Respecto al desarrollo o cuerpo del prospecto- $m$, tras un muestreo significativo y amplio, podemos concluir de forma empírica un conjunto de constituyentes superestructurados de regular presencia y ordenamiento convencional (6):

(6)

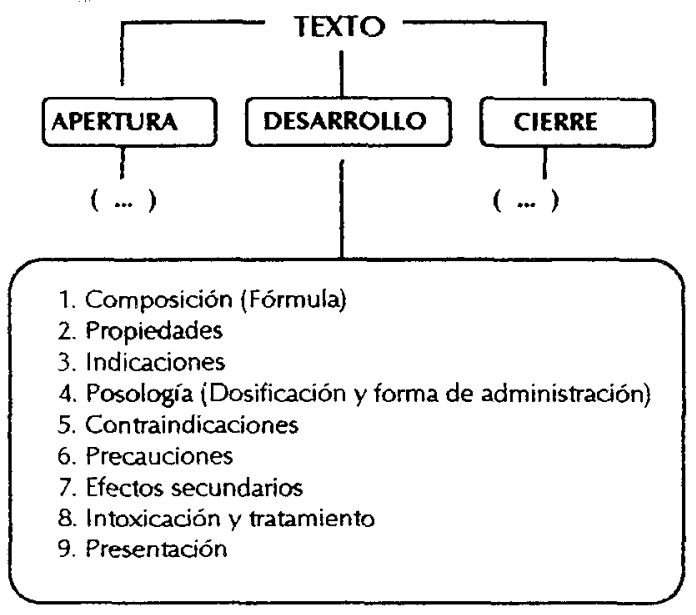


Desarrollo se reescribe $\left(1^{\circ}, 2^{\circ}, 3^{\circ}, \ldots 9^{\circ}\right)$ : un total de nueve temas precisos que se pueden ver ampliados con las unidades Observaciones especiales, Advertencias, Condiciones de conservación, y Nota dirigida a (algún paciente en situación especial, como la mujer embarazada) ${ }^{7}$.

Algunas de estas unidades (composición, propiedades, indicaciones y presentación) suelen disponer de una información semántica nuclear sintetizada ya en el encabezamiento, y que aquí se desarrolla proposicionalmente en una mayor dilatación y flexibilidad gramatical, aunque nunca suelen sobrepasar, cuantitativa y cualitativamente, el estilo y el tono del resumen técnico-científico. Este tipo de recurrencias se puede encontrar, también, en el interior del propio desarrollo, en relación intercategorial(7):

(7)

a.1. Propiedades: «GELIDINA es un preparado dotado de una intensa actividad antiinflamatoria, antipruriginosa y vasoconstrictora tópica».

a.2. Indicaciones: «GELIDINA está indicado en el tratamiento de una gran variedad de afecciones inflamatorias, pruriginosas y alérgicas de la piel, tales como...»

Como puede constatarse en el ejemplo anterior, las relaciones semánticas establecidas entre a.1. y a.2 son de clara recurrencia informativa, aunque, como se verá más adelante, no responden a una mera tautología.

Todos los indicadores o titulares utilizados por el emisor en el desarrollo del texto prospecto- $m$ sirven de guía al lector para facilitarle el reconocimiento de un conjunto macroestructurado coherente y tipificado. Qué duda cabe que, intuitivamente y sin ningún tipo de aviso, la verificación prototípica del prospecto$m$ es espontánea y no ofrece dudas. Los nueve temas axiales del desarrollo más los cuatro complementarios (opcionales, según la retórica aplicada y según las exigencias motivadas por el medicamento) comportan un «aire de familia» macro-categorial. De forma extensional, ligado a la noción de ejemplaridad, y de forma intensional, ligado al conjunto de propiedades (G. Kleiber, 1991), la estructura global del prospecto- $m$ se siente muy justificada en la compensación interna del equilibrio categorial.

Qué duda cabe que, si de nuevo recurrimos a una perspectiva perceptual gestaltiana, las consecuencias del ordo naturalis (propias del encabezamiento) hacen posible una percepción distinta y plural, adoptando un valor diferente,

7 No incluimos en este apartado, aunque sería conveniente en un estudio más amplio y exhaustivo, las unidades exigidas por medicamentos especiales, como: los radiofármacos de uso humano (B.O.E., 7 de mayo, 1993, $\mathrm{n}^{2} 109$ ). 
según el marco co-textual en el que se integre. Es éste el caso de las recurrencias informativas dadas en el interior del desarrollo (véase el ya citado ejemplo a.1 y a.2: Propiedades e Indicaciones) que, distribuido en distintos títulos, va condicionando y constriñendo la interpretación del párrafo y del resto del texto.

Una representación sintáctica de la articulación textual del desarrollo podría explicitar su montaje con la siguiente macroproposición(8):

(8)

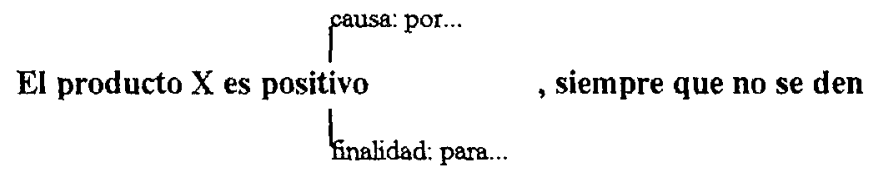 circunstancias desfavorables y, si se dieran circunstancias desfavorables como:... como:... entonces, y sólo entonces, la solución podría ser como:

Por otra parte, sintetizando la macroestructura semántica, se establece una constitución formada por tres grandes bloques modales (9) relacionados, de forma paratáctica, el $1^{\circ}$ con el $2^{\circ}$ adversativamente y el $1^{\circ}$ con el $3^{\circ}$ concesivamente (con inclusión en un marco temporal preciso).

(9)

\section{Bloque eufórico}

COMPOSICION PROPIEDADES INDICACIONES

\section{2ะ Bloque disfórico}

CONTRAINDICACIONES PRECAUCIONES EFECTOS SECUNDARIOS

\section{$3^{2}$ Bloque disfórico-eufórico}


Expresiones como «es de gran utilidad», «es perfectamente tolerado», «no provoca irritaciones», «no provoca molestias», «está perfectamente indicado»,... son predicaciones positivas de un sujeto tematizado principalmente en las variables: denominación de marca, nombre técnico del constituyente fundamental de la fórmula y producto.

Frente al sentido eufórico provocado por este primer bloque, incluido en el mismo el efecto de la «quintaesencia revelada» en la composición, la sensación disfórica del segundo bloque viene determinada por expresiones superficiales que inciden en «deficiencias $X$ del paciente» (responsabilidad del paciente vs responsabilidad del medicamento), en «causaciones de exceso» («con dosis altas...», «con tratamientos prolongados...») y en «randonizaciones» $\mathrm{o}$ inclusiones de elementos al azar («ocasionalmente...», «raramente...». La realidad periférica de la interacciones y las intoxicaciones, aunque negativa en los posibles resultados, es completamente ajena a las cualidades inmanentes del producto descontextualizado, por lo que la oposición entre el aspecto negativo y la solución propuesta se resuelve en una línea de objetividad científica, libre de planteamientos interesados.

Macroestructuralmente, los subtítulos del desarrollo presentan indicaciones rápidas sobre el tipo de texto, orientado al lector y permitiéndole, según sus intereses, ejercitar acciones de selección lectora. Para el receptor desconocedor de las particularidades técnicas del prospecto- $m$, el hecho de resumir su desarrollo, describirlo o concentrarlo, va ligado a un proceso de elaboración cognitiva de información que establece lazos entre las macroestructuras de cada bloque, enmarcando la síntesis informativa, eufórica o disfóricamente, y constituyendo modelos de la realidad (P.N. Johnson-Laird, 1981).

El entramado de cada red de conceptos concreta se va elaborando en torno a los bloques, sin tener en cuenta la segmentación, la ordenación y la relación de los constituyentes de superficie, ni recordando una proposición estática aplicable a cada una de las unidades. Mucho más frecuente y natural es la factura de una expresión macroproposicional recompensadora de las pérdidas léxico-semánticas concretas y renovadora del sentido original.

En un mismo prospecto-m, entre otros términos de carácter técnico y junto a las expresiones de estricta composición, podemos encontrar un número muy elevado de términos vacíos o «eslabones perdidos» (10) para la competencia del lector medio no especializado.

(10)

Ej. prospecto $\mathrm{n}^{\mathrm{O}} 1$ :

pirazolonas (dipirona, propifenazona, fenazona, isopropilaminofenazona, fenibutazona), granulocitopenia, glucosa-6-fosfato-deshidrogenasa, dipirona, glucosaoxidasa, antidepresivos tricícliclos, quinidina, amantadina, anticolinérgico, granulopoyético, glucocorticoides, trombocitopenia, leucopienia, prednisolona, butilbromuro, parasimpatocomiméticos, pilocarpina, cateterismo, hipovolemia. 
Ej. prospecto $n^{\mathbb{2}} 2$ :

concentraciones plasmáticas, metaboliza, secreción tubular, síndrome de Zollinger-Ellison, profilaxis de la hemorragia, síndrome de Mendelson, anamnesis, dispepsias, naturaleza neoplásica, fibroscopia, obstréticos, citrato sódico, creatinina, latrogénicos, monooxigenasas, citrocromo P-450, diazepam, lidocaína, propranolol, teofilina, warfarina, hepatocanalicular, agranulocitosis, pancitopenia, hipoplasia, aplasia, edema angioneurótico, broncospasmo, artralgia.

Sin embargo, esta circunstancia de «hiperprecisión» emisora y selección receptora, se resuelve pragmáticamente en una efectividad informativa macroestructural, con renuncia a la amplificación semántica recuperable por el médico, por el farmacéutico o por el técnico sanitario.

El constituto desarrollo está organizado polifónicamente, de modo que las relaciones establecidas entre las unidades propias de cada bloque reiteran, renuevan, reducen y reinstalan el significado de los distintos modelos a través de un proceso doble de acción y selección.

Los parámetros contextuales no sólo ponen de manifiesto los aspectos relacionados con los comunicantes, sino que también reflejan las relaciones lingüístico-comunicativas entre los comunicantes y el mensaje propiamente dicho (T. Albadalejo y A. García Berrio, 1983). La situación de los interlocutores y el conocimiento experiencial hacen presuponer la vía específica por la que discurre el significado de los «eslabones perdidos», dirigido a un sector reducido de destinatarios para los que el texto adquiere un sentido de «abstract» documental de carácter científico.

La macroacción instructora (impersonal/genérica) frente al acto de fe del destinatario, en un marco general de insuficiencia, deficiencia o enfermedad, reorganiza continuamente la acción por medio de generaciones proposicionales con propósito de saatisfactoriedad pragmática y un amplio macropropósito de "seguridad" (11). 


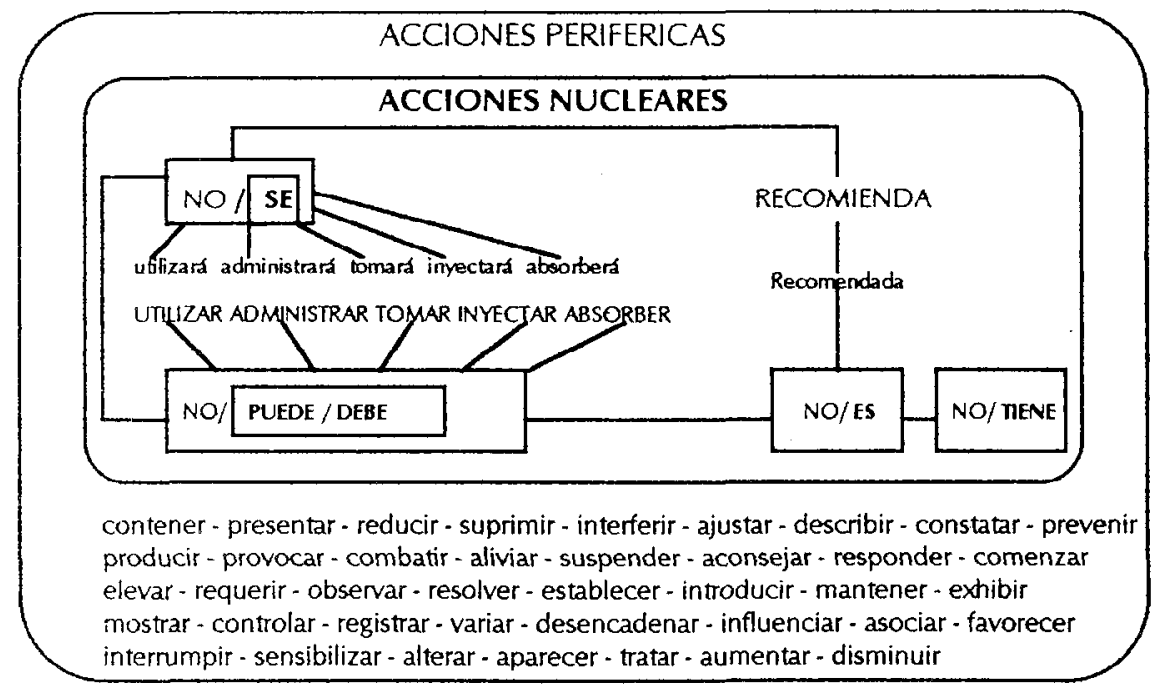

\section{LA DESIGNACIÓN DEL TIPO}

Entendida la definición como operación lingüística (M. Bunge, 1975: 119121), desligada de aspectos ya desestimados («quid rei» et «quid nominis»), el proceso de explicación significativa del definiendum (prospecto-m) aporta una serie de caracteres de fijación tipológica.

El prospecto-m es un comunicado breve de carácter instructivo, impreso en papel y de pequeño formato, sobre un medicamento para uso humano, cuya finalidad es servir de guía al usuario respecto a las acciones a emprender para utilizar ese mismo medicamento.

Frente a posibles definiciones de carácter operacional o de carácter causal, la definición anterior responde a criterios clasemáticos que permiten la ampliación y exhaustividad de la definición hasta el límite en que puede dejar de ser operativa («... en el que se expone la composición cualitativa y cuantitativa del producto, la forma farmacéutica y el contenido en peso, en volumen o en unidad de toma, la categoría farmacoterapéutica, el tipo de actividad, las contraindicaciones, las precauciones de empleo adecuadas, las intereacciones medicamentosas,...») (12) 


\section{CLASE DE TEXTO}

PROSPECTO

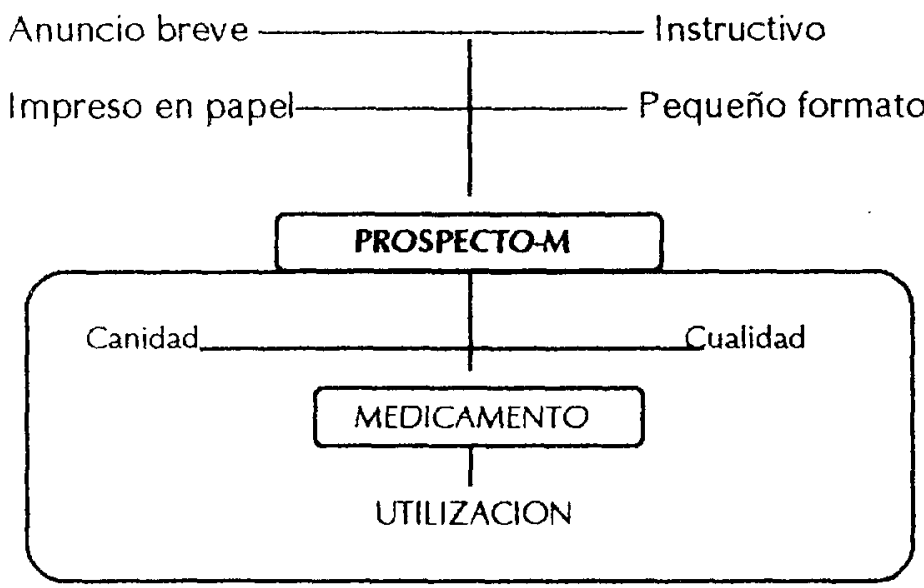

Sin embargo, partiendo de este planteamiento de inserción, correspondencia y exhaustividad, los criterios de designación del tipo se pueden basar en una selección constituida por auténticos elementos tipológico-textuales.

$1^{\circ}$ DIMENSIONALIDAD $=$ Comunicados breves

$2^{-} \quad$ SOPORTE - Documental

3 CANALIZACIÓN = Impreso en papel (escrito)

$4^{\circ}$ FORMATO $=$ Pequeño formato

$5^{2} \quad$ CÓDIGO $=$ Semiótica mixta (predominio lingüístico)

$6^{\circ}$ CONTEXTO DE EMISIÓN = Científico/Técnico

$7^{9}$ OBJETO TEMÁTICO $=$ Medicamento $\mathrm{X}$

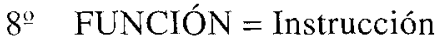

9- MOTIVACIÓN DE PROPÓSITO E INTENCIÓN = Responsabilidad (sometido a lógica deóntica: regulado por Real Decreto)

$10^{\circ}$ ESTRUCTURA $=$ Superestructurado y estereotipado.

De cualquier forma, si las posibilidades de selección de criterio son varias y el tipo puede responder a cualquiera de ellas, la superestructura textual resulta idónea como marcadora de identificación textual de primer orden, relacionada con una macroproposición temática y articulada en categorías que, a su vez, giran también en torno a un núcleo temático o subtema. 
El texto prospecto- $m$ es un tipo que responde a una superestructura abundosa y que se configura con una prototipicidad muy densa respecto a la categoría (efectos prototípicos, «by-product» de las estructuras de las categorías).

Por otra parte, el control logicial impuesto por el paradigma determina la relación del sistema con el mundo exterior enmarcado por el marco conceptual (E. Morin, 1991). Disociación, asociación, rechazo y unificación rigen, prelógicamente, los caracteres lógicos y prelingüísticos que se actualizan en el discurso, sin que las leves fluctuaciones de estructura modifiquen la organización del sistema.

Los componentes elementales de la estructura paradigmática se disponen en una relación:

$\begin{array}{lr}\text { SUJETO } & \text { OBJETO } \\ \text { CUALIDAD } & \text { CANTIDAD } \\ \text { CAUSALIDAD } & \text { FINALIDAD }\end{array}$

Relación ésta que se yuxtapone al modelo actancial en el esquema básico del marco de integración global del prospecto-m (13); macroestructura regidora de los distintos cuerpos de estructuras superficiales, que puede representarse en forma de macroproposición articulada.

(13)

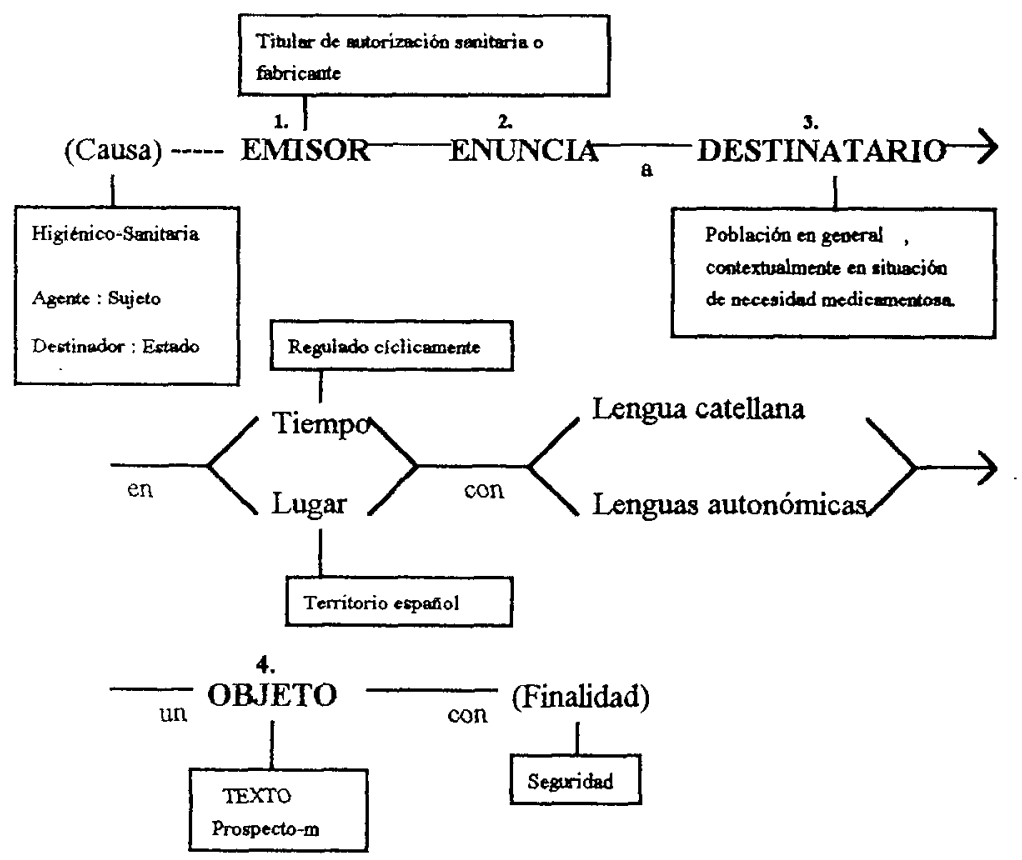


La fusión paradigmática con la representación de predicados, actantes y circunstantes, se ve inscrita, a su vez, en un esquema paradigmático superior (14), en el que los conceptos de VIDA y la MUERTE se disponen en polos opuestos, pero de forma evolutiva y asimétrica.

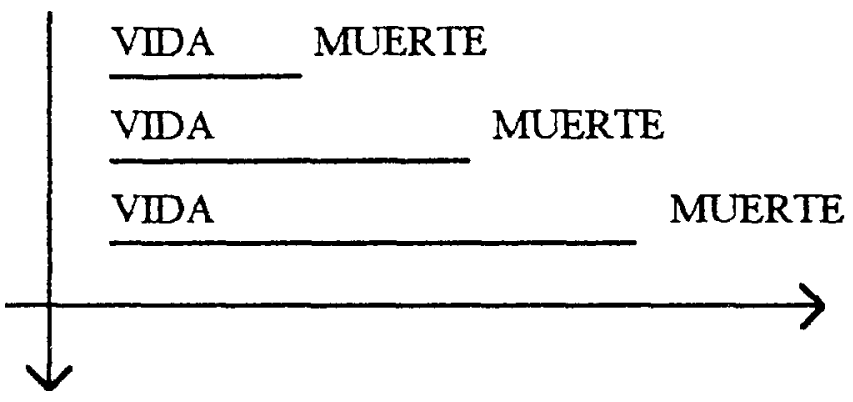

En esta representación dinámica, bajo la permanencia de la tensión conceptual, se puede apreciar una ilusoria descompensación cronológica, debido a una constante y manifiesta ampliación del dominio vital. La modificación del paradigma social en favor de una mayor calidad de vida vs cantidad de vida, paradójicamente ha incrementado también la cantidad de vida, constituyéndose el concepto de medicamento en panacea de esa necesidad irreductible de supervivencia e inmortalidad del «eterno mortal» (V. Jankelevitch). Magia y medicina, oración y pócima, traducen un estado de defensa práctica de orígenes remotos. La enfermedad y el envejecimiento, programado o sobreimpuestos, se manifiestan fenoménicamente como enfermedades concretas, para las que el medicamento es un buen instrumento de domesticación.

Coincidimos plenamente con Morin en que la reforma de la muerte consiste en la prolongación de la vida humana para que el individuo pueda llevar a término su nuevo ciclo de desarrollo (1970-74: 371). No sólo, pero sí de manera muy práctica e inmediata, el concepto «medicamento» amplifica el dominio de la palabra mágica y exige a la propia palabra la difusión y la explicación instructora. Desde esta perspectiva, y evitando las múltiples referencias históricas y antropológicas, el texto del prospecto- $m$ pasa a formar parte de esa clase de textos que, obedeciendo a un plan global subyacente, intentan iluminar la expansión individual del destino biótico. Como instrumento favorecedor de vida, el prospecto-m se ve ligado al paradigma social, del que se desprende un undécimo criterio: PARADIGMA = Potenciador de vida o retardador de muerte.

Si bien los criterios para determinar un tipo pueden ser múltiples, entendemos que los aplicados al texto del prospecto- $m$ alcanzan el suficiente grado de pertinencia como para hacer rentable su designación. No obstante, e incidiendo en el perfil preciso de la superestructura del prospecto- $m$, la estandarización y 
fijeza de este tipo de texto se convierte en el rasgo diferenciador más compacto de su atribución tipológica. Junto a la función instructora, un rasgo de diseño estructural tan relevante como el encabezamiento no hace sino justificar el ahormamiento distintivo del tipo.

Si aceptamos metodológicamente la subdivisión de miembros de la comunidad linguística, a la manera de Putnam, en dos clases bien diferenciadas: los expertos y los inexpertos o hablantes usuales (H. Putnam, 1975: 144-146; J. L. Cifuentes, 1992: 164-168), en la situación receptora ante el prospecto- $m$ (dirigido a la totalidad de consumidores en situación de necesidad medicamentosa, con la sola exigencia de las situaciones reguladas por los símbolos de la apertura textual y las información del bloque disfórico incluido en el desarrollo) se adoptará una postra interpretativa, correspondiente a criterios, y otra alternativa, correspondiente a estereotipos ${ }^{8}$.

En la estrategia analítica adoptada, la sintaxis u ordenamiento de ambos planteamientos, que se ha llevado a cabo simultáneamente, pero sin interferencias operativas, nos ha permitido el empleo de marcadores concretos para la definición crítica del tipo. Pero, también las asociaciones semánticas del estereotipo, confluyentes en una manifiesta eficacia social, nos han revelado una realidad sometida a grado, que va desde el mero reconocimiento perceptual (objeto-textoprospecto-m: objeto que, $1^{\circ}$, acompaña físicamente al objeto referencial; $2^{\circ}$, habla del objeto referencial), sin interés textual para el destinatario, $y$, por tanto, sin eficacia comunicativa, hasta una estructura muy simplificada, configurada por la demanda práctica, inmediata y concreta del destinatario inexperto (¿qué? /denominación popular/; ¿para qué? /contra qué dolencia principal/; ¿cómo? / vía/; ¿cada cuánto? /circunstancias y temporales asociadas/) y la satisfactoriedad del texto en ese campo preciso, dispuesta con prioridad jerárquica y completamente ajena a las «cadenas perdidas» de información.

Aunque, frente al conjunto ordenado de los constituyentes del estereotipo, los criterios han aportado elementos de reconocimiento mucho más afinados, el estereotipo ligado a prospecto- $m$ no yerra con contribuciones inoportunas de adherencia social, ya que los rasgos poseídos son auténticos rasgos de información prioritaria seleccionados del paradigma, después de haberse eleminado las ambiguiedades y reducido las complicaciones interpretativas, tendiendo a lo que los psicólogos de la gestalt denominaron «ley de la prägnanz».

Desde una perspectiva de comunicación social, la representación del prospecto$m$ como meme (R. Dawkins, 1976), o «culturema», expresado textualmente y soportado documentalmente, en un contexto de emisión médico-farmacéutica,

\footnotetext{
Entendemos aquí el concepto de estereotipo, con la modificación aportada por Putnam: «creencia acerca de los objetos estándar en situaciones estándar», frente a la descripción tradicional, en la que un estereotipo constituía «una descripción normalizada de los rasgos típicos de la clase». Para una espléndida reflexión sobre los conceptos «prototipo y estereotipo» y clarificaciones de interés sobre la teoría de prototipos, véase J. L. Cifuentes Honrubia (1992: 133-177).
} 
se construye —en tanto que texto de información pragmática (J. Mosterín, 1993: 25) - como información básicamente práctica sobre una entrada general de tipo descriptivo, con una finalidad de función persuasiva (M. Metzeltin, 1988: 19) sustentada en las obligaciones del emisor y en los intereses del destinatario.

Las coincidencias estructurales, deducibles de la yuxtaposición de los resultados de ambos enfoques, ratifican la idoneidad de la designación, en cuya descripción teórica, el orden, la regularidad y la jerarquía de los constituyentes del tipo se manifiestan constantes con una significatividad más pertinente que la propia estructura, en las zonas nucleares de compleja superestructura y en las zonas nucleares de la simple reducción estándar, lo que confirma, frente a la extrema simplificación sociolingüística, la identificación nuclear con el axis de la categoría prototípica concreta.

\section{REFERENCIAS BIBLIOGRÁFICAS}

ALBADALEJO, T. y GARCÍA BERRIÓ, A. (1983): «La Lingüística del Texto», en Introducción a la Lingüística, Alhambra, Madrid.

AMAT, Nuria (1988): Documentación Científica y Nuevas Tecnologías de la Información, Pirámide, Madrid.

ARNHEIM, Rudolf (1954-1974): Arte y Percepción Visual, Alianza Forma, Madrid, 1979.

BEAUGRANDE, R.A. (1981): Introduction to Textlinguistics, Longman, London. BUNGE, M. (1975): La investigación científica, Ariel, Barcelona.

CIFUENTES HONRUBIA, José Luis (1992); «Teoría de prototipos y funcionalidad semántica», en ELUA, no $8,133-177$.

CLARK, E. (1988): La publicidad y su poder. Las técnicas de provocación al consumo, Planeta, Barcelona.

CURRAS, Emilia (1988): La Información en sus Nuevos Aspectos, Paraninfo, Madrid. COSERIU, Eugenio (1977): El hombre y su lenguaje: estudios de teoría y metodología cientifica, Gredos, Madrid.

DIJK, T.A. van (1978): La Ciencia del Texto, Paidós Comunicación, Barcelona, 1983. GÓMEZ, Juan Pedro (1991): «De los Preámbulos y Liminares Constitucionales como Metatextos (En el Texto Constitucional Hispanoamericano)», en Estudios de Lingüística, Universidad de Alicante, ํㅡㄱ.

HOFSTADTER, Douglas, R. (1979): Gödel, Escher, Bach: Un Eterno y Grácil Bucle, Tusquets, Barcelona, 1987-1989 (tercera ed.).

ISENBERG, Horst (1983): «Cuestiones fundamentales de tipología textual», en Lingüística del texto, Compilación de E. Bernárdez, Arco/Libros, Madrid, 1987, 95-129.

JOHNSON-LAIRD, P.N. (1981): «Comprehension as the construction of mental models», en The Psychological Mechanims of Language, Philosophical Transaction of the Royal Society of London, The Royal Society and the British Academy. 
KLEIBER, Georges (1991): «Prototype et prototypes: encore una affaire de famille», en Sémantique et Cognition, D. Dubois (ed.), CNRS, Paris, 103-129.

LOTMAN, Jurij M. y USPENSKIJ, B. A. (1973/1979): «Mito, nombre y cultura», en Semiótica de la Cultura, Lotman y Escuela de Tartu, Cátedra, Madrid, 1979.

METZELTIN, Miguel (1988): Lingüistica textual y análisis de textos hispánicos, Secretariado de Publicaciones e Intercambio Científico, Universidad de Murcia. MORIN, Edgar (1970): El hombre y la muerte, Kairós, Barcelona.

MORIN, Edgar (1991): El Método. Las Ideas, Cátedra, Madrid, 1992.

MOSTERÍN, Jesús (1993): Filosofia de la cultura, Alianza Universidad, Madrid.

PÉNINOU, G. (1976): Semiótica de la publicidad, Gustavo Gili, Barcelona.

PETÖFI, J.S. y GARCÍA BERRIO, A. (1978): Lingüística del texto, Alberto Corazón, Comunicación, Madrid.

PUTNAM, Hilary (1975): «El significado de "Significado"», en La búsqueda del significado, Valdés Villanueva (ed.), Tecnos-Universidad de Murcia, Madrid, 1991, 131-194.

RAMÓN TRIVES, Estanislao (1979): Aspectos de semántica lingüístico-textual, IstmoAlcalá, Madrid.

ROCK, Irvin (1975): An Introduction to Perception, New York: Macmillan.

ROCK, Irvin (1984): La Percepción, Prensa Científica, Labor, Barcelona, 1985.

SÁNCHEZ CORRAL, L. (1990): «El nombre propio como imagen semiótica del referente», en ELUA, 6, Alicante.

ULLMANN, S. (1976): Semántica, Aguilar, Madrid.

VERA LUJÁN, Agustín (1990): «Para una caracterización tipológica de los Textos Constitucionales (A propósito de los Textos Constitucionales Iberoamericanos)», en Estudios de Lingüística, Universidad de Alicante, $\mathrm{n}^{\circ} 6$.

VIEHWEGER, Dieter (1983): «Finalidades de acción linguística en textos imperativos», en Lingüística del texto, Compilación de E. Bernárdez, Arco/Libros, 1987, 229-263.

WITTGENSTEIN, Ludwig (1957): Tractatus logico-Philosophicus, Alianza, Madrid, 1973-1984 (sexta ed.). 